This item was submitted to Loughborough's Research Repository by the author.

Items in Figshare are protected by copyright, with all rights reserved, unless otherwise indicated.

\title{
Nanofiltration: a technology for selective solute removal from fuels and solvents
}

PLEASE CITE THE PUBLISHED VERSION

PUBLISHER

Elsevier / ( ) The Institution of Chemical Engineers

VERSION

AM (Accepted Manuscript)

LICENCE

CC BY-NC-ND 4.0

\section{REPOSITORY RECORD}

Tarleton, E.S., J.P. Robinson, and Jian-Shen Low. 2009. "Nanofiltration: A Technology for Selective Solute Removal from Fuels and Solvents". figshare. https://hdl.handle.net/2134/4356. 
This item was submitted to Loughborough's Institutional Repository (https://dspace.lboro.ac.uk/) by the author and is made available under the following Creative Commons Licence conditions.

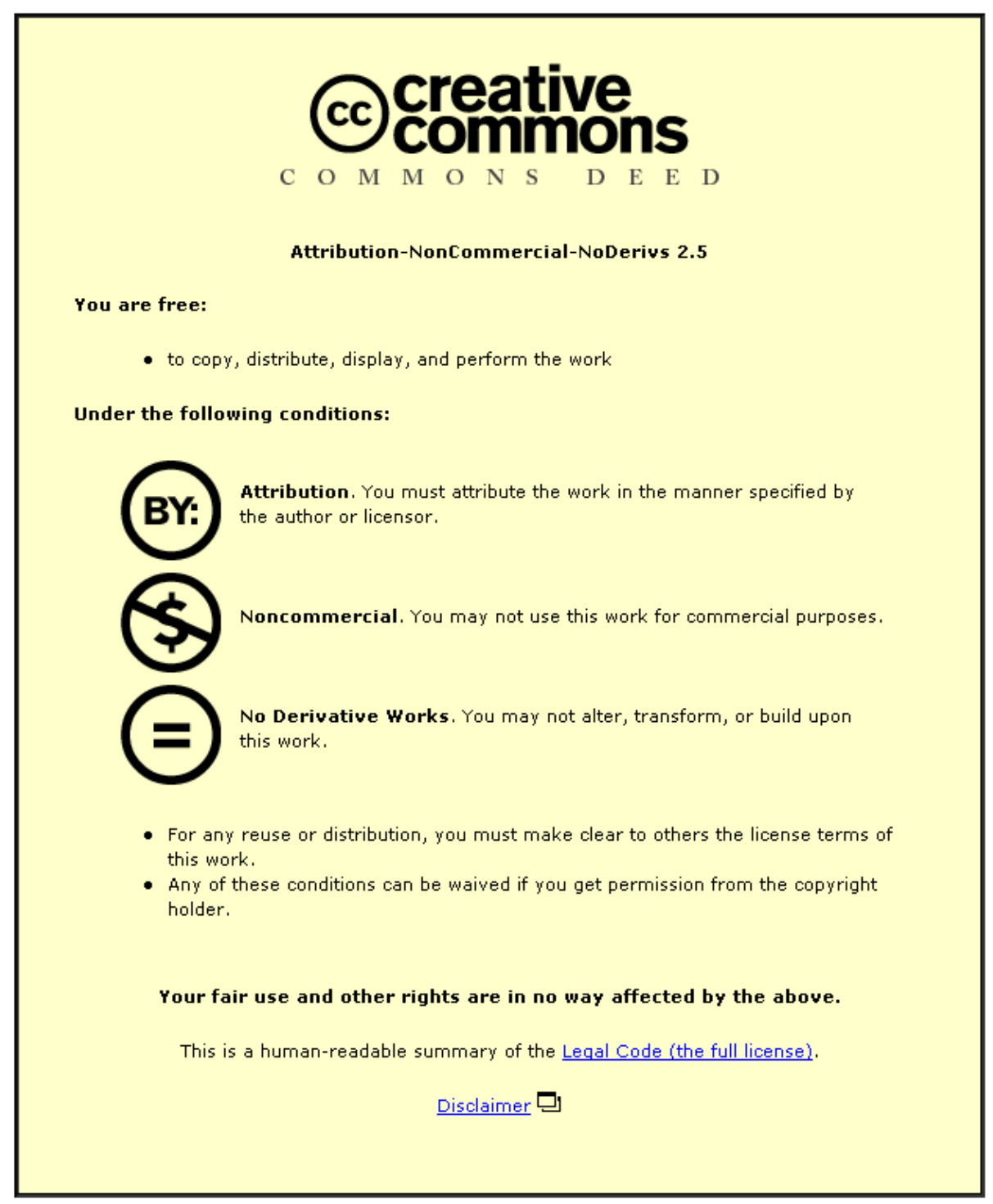

For the full text of this licence, please go to: http://creativecommons.org/licenses/by-nc-nd/2.5/ 


\title{
NANOFILTRATION: A TECHNOLOGY FOR SELECTIVE SOLUTE REMOVAL FROM FUELS AND SOLVENTS
}

\author{
E.S. Tarleton ${ }^{1}$ (e.s.tarleton@lboro.ac.uk), J.P. Robinson ${ }^{2}$ and J.S. Low ${ }^{1}$ \\ ${ }^{1}$ Advanced Separation Technologies Group, Department of Chemical Engineering, Loughborough \\ University, Loughborough, Leicestershire LE11 3TU, UK. \\ ${ }^{2}$ now at School of Chemical \& Environmental Engineering, The University of Nottingham NG7 \\ 2RD, UK.
}

\begin{abstract}
This paper describes the principal features of solvent resistant nanofiltration, and in particular its potential in fuel processing. Experimental data for both fuel simulants and a representative petrol fuel are presented to illustrate the salient features.

The solute rejection mechanism for low polarity mixtures was size exclusion with a membrane cutoff in the region of 1-2 $\mathrm{nm}$. The extent of solute rejection was dependent on the degree of membrane crosslinking, the membrane swelling induced by the feed and the applied (filtration) pressure. Nanofiltration experiments with the petrol fuel showed a good correlation with the data obtained for the fuel simulants, both in terms of permeate flux and solute rejection. Provided that higher polarity oxygenates were not present in the fuel, it was possible to remove undesirable polynuclear aromatic and organometallic solutes to an extent that was sufficient to reduce valve deposits (by 64\%) and emissions gases (by up to 17\%) in engine tests. These improvements significantly better the changes in engine performance that are brought about by the more traditional addition of fuel additives such as detergents. The technology provides a method for removing undesirable solutes from mixtures without the need for excessive energy input.
\end{abstract}

\section{KEYWORDS}

Nanofiltration, fuel, membrane, solvent, solute.

\section{INTRODUCTION}

The possibility of using polymeric nanofiltration membranes for non-aqueous separations has been explored in recent years. Examples include the recovery of pharmaceutical catalysts from solvents such as dichloromethane, tetrahydrofuran and acetone [Scarpello et al., 2002] and solvent recovery in the food industry such as hexane from vegetable oil [Stafie et al., 2004]. The use of membrane technology in the petrochemical industry has also been considered, and in some cases applied. For instance, in the dewaxing of lubricating oil [Gould et al., 1997], the removal of sulphur from naphtha [White et al., 2005], the removal of metallic compounds from kerosene and gas-oil [Bitter et al., 1992] and the separation of heavy components from gasoline-based fuels [Millington and Nijmeijer, 2005]. A recent review [Vandezande et al., 2007] gives a comprehensive listing of reported applications in food chemistry, petrochemistry, catalytic and pharmaceutical engineering.

The application of solvent resistant nanofiltration (SRNF) in petroleum processing to produce a cleaner gasoline (petrol) fuel is of particular interest in this paper. The technology has the potential to deliver products without the addition of thermal energy, which is appealing given the current cost of energy and ongoing environmental concerns. Improvements in quality can be achieved by the selective removal of components, intrinsic to the fuel, which contribute to the fouling of an engine. Typical concentrations of impurities can vary dramatically, but are of the order of $10 \mathrm{ppb}-100 \mathrm{ppm}$ and examples include 
- Organometallic (OM) species, particularly copper and iron compounds

- Sulphur bearing compounds such as mercaptans and thiophenes

- Poly-nuclear aromatics (PNAs), i.e. substances with two or more benzene rings in their chemical structure.

OMs, PNAs etc cause fouling of engine inlet valves and fuel injectors, which in turn can adversely affect all aspects of engine performance. For instance, inlet valve deposits (IVDs) are caused by fuel droplets coming into contact with the hot surface of the valve, resulting in a residue after evaporation of the volatile components. A build-up of residue can restrict fuel and air passage into the combustion cylinder, which in turn results in reduced power, increased fuel consumption and an increase in environmentally-sensitive emissions such as $\mathrm{NO}_{x}$ gases and particulate matter. Fuel injectors are affected in a similar way. Coking of the nozzle disrupts the spray pattern, which is critical to the efficient combustion of the fuel, with a subsequent negative impact upon overall engine performance. The traditional method for preventing residue build-up is to add organic detergents such as polyisobutene (PIB) derivatives to the fuel. However, fuels with very high levels of residual impurities may not respond to detergents at economic treat-rates, and can even result in increased IVDs due to adverse reactions with the detergent. Additionally, detergents contribute to the overall cost of the fuel, are considered by some to be hazardous to health, and may give a varied response in different engines and under different operating regimes.

In this paper experimental results obtained with fuel simulants, i.e. pure solvents or a binary mixture of pure solvents, together with a known dissolved solute, and a typical petrol fuel containing many solutes, are presented. The data for the simulants, whilst being generally applicable to a range of industries in which non-aqueous processing is required, are used to highlight the key factors that influence separation performance in the SRNF of fuels. These data are related to the filtration performance observed with the petrol fuel and potential benefits of the technology are demonstrated by the results of engine tests.

\section{METHODS AND MATERIALS}

The principal apparatus used in the nanofiltration experiments is shown schematically in Figure 1. An air-driven pump caused the process mixture to move through a standard Osmonics DESAL membrane module (wetted area $=75 \mathrm{~cm}^{2}$ ) at crossflow rates up to $0.7 \mathrm{l} / \mathrm{min}$ and constant filtration pressures up to $800 \mathrm{kPa}$. The retentate passed through a heat exchanger and back into the feed reservoir. The permeate was either also returned directly to this reservoir or sampled for subsequent solute rejection analysis by UV-vis spectroscopy or refractive index; rejection here is defined as $1-C_{p} / C_{f}$ where $C_{p}$ is solute concentration in the permeate and $C_{f}$ is solute concentration in the feed. Steady state measurements of solute rejection and permeate flux were typically repeatable within $\pm 1 \%$. A similar, but uprated, apparatus to that shown in Figure 1 was also available on a periodic basis which facilitated some additional measurements at crossflow rates up to $4 \mathrm{l} / \mathrm{min}$ and pressures up to $2000 \mathrm{kPa}$ [see also Tarleton et al., 2005a]. All nanofiltration experiments were performed using one litre of a solvent/solute mixture with a $10 \%$ stage cut.

Alkane, aromatic and alcohol solvents were used, either solely or as binary mixtures (see Table 1). These span a range of polarity as evidenced by their solubility parameter $\delta=14.3-29.2 \mathrm{MPa}^{0.5}$ and were intended to be representative of the classes of solvents that can be found in a petrol fuel (e.g. xylene is representative of aromatics, $n$-heptane is representative of paraffins). In some membrane swelling determinations, distilled water, either in its pure state or mixed in equal proportion with methanol, was used to expand the data range up to $\delta=47.8 \mathrm{MPa}^{0.5}$. All solvents had initial purities in excess of 99\%. Ten solutes, which can be classed as either PNAs or OMs with molecular weight (MW) in the range 154-612 $\mathrm{g} \mathrm{mol}^{-1}$, were available; the sulphur bearing compounds thiophene (MW $84 \mathrm{~g} \mathrm{~mol}^{-1}$ ) and 1-butanethiol (MW $90 \mathrm{~g} \mathrm{~mol}^{-1}$ ) were also tested but the nanofiltration membranes were unable to bring about their separation from solution. The solutes 
were chosen to be representative of those typically present in a petrol fuel, their ability to span the spectrum of membrane rejection from 0 to 1 , and the ability to dissolve at concentrations up to 75 ppm in the chosen solvents. Due to analysis restrictions, only a single solute was used in each experiment.

A number of composite, two or three layer, flat sheet membranes were utilised. The majority of experiments reported were performed using polydimethylsiloxane (PDMS)/polyacrylonitrile (PAN) membranes. The PDMS acted as the selective layer whilst the inert PAN, which was essentially non-swelling and of circa $40 \mu \mathrm{m}$ pore size, acted as a support layer; in some cases an additional (also inert and non-swelling) cellulose backing sheet was also present to provide additional mechanical strength. In a filtration experiment the dense PDMS layer, which exhibited no manufactured/visible pores, faced toward the feed mixture and membranes were available with initial (unswollen) PDMS thicknesses between $1 \mu \mathrm{m}$ and $10 \mu \mathrm{m}$. During manufacture the membranes were thermally and/or radiation crosslinked to provide structural integrity and chemical stability. Molecular weight cut-off (MWCO) values were typically in the range $300-500 \mathrm{~g} \mathrm{~mol}^{-1}$ and highly dependent on the solvent and type of solute used in the determination; no manufacturer quoted values were available for the PDMS/PAN membranes. Once an initial amount of either xylene or heptane solvent had been permeated through a new membrane to remove any residues there was no need for further pretreatment and no degradation in membrane performance could be observed over prolonged periods of use [see Robinson, 2004]. A minority of experiments were performed with Starmem ${ }^{\mathrm{TM}} 122$ polyimide (PI) membranes in order to extend the range of data; selective layer thickness here was difficult to determine reliably, but estimated at $75 \mu \mathrm{m}$. MWCO was quoted by the manufacturer as $220 \mathrm{Da}$ and 'based on $90 \%$ rejection of normal alkanes dissolved in toluene'. Representative micrographs of the membranes are presented in Figure 2 (Table 1 shows additional data). It is noted that full details of membrane chemical composition and manufacturing steps were not available to the authors for reasons of commercial confidentiality.

A novel laboratory apparatus has previously been developed to determine the swelling of an 'as manufactured' membrane in a given solvent [Tarleton et al. 2005b; 2006a]. In brief, a sample of membrane is placed in a flat-bottomed dish, a $10 \mathrm{~mm}$ diameter spacer is rested on top of the sample and a linear measurement probe (resolution $0.1 \mu \mathrm{m}$ ) is positioned over the spacer and connected to an electronic column gauge. Subsequent introduction of circa $5 \mathrm{ml}$ of solvent initiates any swelling and allows a quantitative measurement to be taken. With the addition of a support frame and cantilever bar that pivots about a bearing mount in one end, it is possible to impose a pressure up to $2000 \mathrm{kPa}$ upon a membrane sample prior to, and throughout, solvent induced swelling.

The apparatus and procedures described were intended to provide fundamental data with which to develop understanding and elucidate transport mechanisms for a group of solvents and solutes, e.g. fuel simulants. Further tests were performed in order to assess the nanofiltration of a petrol fuel containing circa $60 \%$ aromatics, 30\% paraffins and 10\% olefins (as determined by gas chromatography analysis) as well as a range of dissolved solutes at ppm level concentrations; this is denoted in the paper as the base fuel. Whilst the exact nature of the contaminating solutes could not be routinely determined, they were known to be a blend including OMs, PNAs and sulphur bearing compounds. Sufficient amounts of the fuel were filtered with a PDMS/PAN membrane to facilitate a sequence of representative engine tests. A standard engine test bed was used to evaluate the performance of the base fuel, permeated fuel, retentate fuel (i.e. that remaining on the feed side of the membrane after a filtration test) and the base fuel plus a detergent additive that is typically added to a commercial fuel in order to reduce engine deposits (i.e. denoted as additivated fuel).

\section{RESULTS, ANALYSIS AND DISCUSSION}


The results presented are typical of those obtained and, for the fuel simulants, only sufficient data are presented to enable the work with the petrol fuel to be better interpreted and placed into context. For detailed work regarding the fuel simulants the reader is referred to some of the authors other publications which include modelling and more in-depth debate of fundamental solvent/solute transport mechanisms, e.g. solution-diffusion vs. pore flow for low polarity systems [Robinson et al., 2005], and surface rejection/swelling equilibria [Tarleton et al., 2006a; 2006b]. The fuel simulant results are representative of typical behaviour with low polarity solvents and single solutes as well as the swelling behaviour which can be expected with solvent resistant membranes. There was general agreement in trends between the nanofiltration data for the fuel simulants and petrol fuel.

It is noted that in no instances during nanofiltration did fouling due to solute accumulation at the membrane occur, presumably as a consequence of the low concentration of solute(s) in a feed, and solvent flux was independent of solute concentration up to the $75 \mathrm{ppm}$ maximum tested. Moreover, mixtures of low polarity solvents, including those constituting the base petrol fuel, did not undergo separation upon passage through a membrane.

\section{Fuel Simulants}

The simplest behaviour in SRNF is demonstrated by low polarity solvent systems, e.g. i-octane, nheptane, xylene etc. By way of example, Figure 3 shows that for a fixed crossflow, xylene solvent and 9,10-diphenylanthracene (PNA) solute at $20 \mathrm{ppm}$ concentration, the flux-pressure relationship is linear in accordance with Darcy's Law for all the tested membranes. The level of flux for a given pressure is dependent on the membrane used and influenced by the thickness of the selective PDMS layer. Whilst a doubling in flux could intuitively be expected for a membrane with a $1 \mu \mathrm{m}$ PDMS layer compared to an otherwise identical membrane with a $2 \mu \mathrm{m}$, the situation is complicated by solvent induced swelling as shown in Figure 4.

The extent of membrane swelling is strongly influenced by the solubility parameter $(\delta)$ of the solvent relative to the $\delta$ value for the polymer(s) comprising the membrane. For a xylene solvent with $\delta=18.2 \mathrm{MPa}^{0.5}$, a PDMS layer was observed to swell by $123 \%, 115 \%$ and $50 \%$ for the membranes designated 'radiation, $2 \mu \mathrm{m}$ ', 'radiation, $1 \mu \mathrm{m}$ ' and 'thermal, $1.5 \mu \mathrm{m}$ ', respectively. It is clear that the purely thermal treated membrane is more crosslinked which leads to the lower flux levels seen in Figure 3. However, there was a trade-off between flux and rejection whereby a lower flux was accompanied by a relatively high solute rejection and vice versa. An increased filtration pressure also led to a progressive, but non-linear, improvement in solute rejection toward a limiting value [Tarleton et al., 2005a] which was often accompanied by a significant reduction in swollen PDMS thickness [Tarleton et al., 2005b].

Figure 5 shows typical examples of PNA and OM rejection vs. maximum solute size for two different PDMS membranes at a fixed filtration pressure with xylene solvent. Whilst correlations with solute molecular weight were unreliable and relatively poor, correlations with maximum solute size were much improved and showed a typically sharp transition in rejection around $1.5 \mathrm{~nm}$ (equivalent to a MWCO of circa $350-400 \mathrm{~g} \mathrm{~mol}^{-1}$ for the tested solvent/solute combinations). Such behaviour is indicative of the selective PDMS layer rejecting low-polarity, minimally interacting solutes on the basis of size-exclusion and viscous solvent transport to an extent dependent upon the degree of swelling induced change in size of the membrane transport regions. When the membrane was more crosslinked, for example the membrane labelled 'thermal $1.5 \mu \mathrm{m}$ ' in Figure 5, then rejection was higher with a given solute. In general, solvents inducing a larger amount of swelling yielded higher permeate flux and lower solute rejection than poorer swelling solvents; for example with reference to Figure 5, comparable experiments for the 'radiation $2 \mu \mathrm{m}$ ' membrane and heptane induced greater membrane swelling and a 55\% increase in permeate flux that was accompanied by rejections close to unity at maximum solute sizes nearer to $2 \mathrm{~nm}$. 
Interpreting flux and rejection behaviour in nanofiltration is challenging when more polar solvents are present and some of the issues that arise are discussed below in the context of experiments with the petrol fuel.

\section{Petrol Fuel - Filtration Performance}

\section{General Considerations}

As the exact nature and concentration of the contaminating solutes in the base petrol fuel, or the permeate and retentate obtained by nanofiltration, could not be routinely determined it was important to develop a method to evaluate separation performance.

After some initial scoping experiments, UV-vis spectroscopy was identified as being a suitable analysis method. Solute impurities will contribute to absorbance at various wavelengths and Figure 6 shows that absorbance of the tested petrol fuel at $410-430 \mathrm{~nm}$ is relatively high which is advantageous. However, although UV-vis is capable of determining if there is a lower level of residual impurities, it cannot quantify which particular solutes from a number of species may have been removed by a filtration process. Despite this restriction, and noting that absorbance at any given wavelength is proportional to the concentration of a particular species and also cumulative, a term denoted 'fuel clean-up' was used to quantify solute removal. Higher values are indicative of a better retention of solutes by a membrane and the term is formally defined as $1-A_{p} / A_{f}$ where $A_{p}$ and $A_{f}$ are the absorbance of the feed and permeate respectively at any given wavelength; these values correspond to the total concentration of impurities in the permeate and feed. Below an absorbance value of 0.9 , the absorbance-concentration profiles for the solutes within the petrol fuel are linear [see Robinson, 2004], and hence the absorbance ratio is identical to the ratio of the total concentration of impurities.

To determine the most suitable UV-vis wavelength for fuel clean-up measurements, nanofiltration experiments with the base petrol fuel and a radiation crosslinked, $2 \mu \mathrm{m}$ PDMS/PAN membranes were performed; representative results for all measured wavelengths and a filtration pressure of $500 \mathrm{kPa}$ are shown in Figure 6. The ideal reference wavelength is one which exhibits an appreciable fuel clean-up and a relatively high absorbance. Fuel clean-up at wavelengths below $400 \mathrm{~nm}$ is relatively low and thought to correspond to (smaller) 2-4 ring PNAs. Whilst absorbance of these molecules is strong in this region [Perkampus, 1992], studies with the fuel simulants showed that small PNAs are subject to low rejection by membranes of this type (see, for example, Figure 5). Although fuel clean-up at wavelengths above $450 \mathrm{~nm}$ is relatively high the absorbance is low, which is likely to lead to a large degree of error in calculations. The most promising region for clean-up measurement is $400-450 \mathrm{~nm}$ and $420 \mathrm{~nm}$ was chosen for subsequent measurements. Fuel clean-up usually corresponded to an observed change in colour between the feed and permeate, and is due to the removal of larger OMs and PNAs.

Some preliminary filtration studies were also performed using a PDMS/PAN membrane and a petrol fuel rich in organic copper and iron compounds (not the fuel referred to elsewhere in this paper). Elemental analysis showed the permeate to be considerably depleted in both copper and iron, whilst the concentration of both in the retentate increased. Subsequent analysis of the used membrane showed that no copper or iron was present on the surface of the PDMS which suggests that the separation mechanism does not involve adsorption to the membrane material, a result that is consistent with observations for the fuel simulants. Additional mass balance calculations on the feed, permeate and retentate samples further confirmed these findings.

\section{Effects of Pressure}

A typical fuel simulant system exhibited increasing solute rejection with increasing filtration pressure and notionally similar behaviour was observed for the base petrol fuel. Fuel clean-up 
improved with increasing pressure for all the measured UV-vis wavelengths and Figure 7 shows representative data at $420 \mathrm{~nm}$. With the petrol fuel a limiting rejection was not generally achieved and fuel clean-up tended to increase progressively up to the maximum available pressure (2000 $\mathrm{kPa}$ ). Such a trend is most likely due to the multiplicity of solute components and the relatively large range of solute sizes present in the fuel. Of the components which contribute to the net absorbance at any specific wavelength it is likely that some are un-rejected, some are completely retained and the rest are subject to an intermediate rejection.

A plot of permeate flux vs. filtration pressure, from which permeance is calculated, exhibited a linear relationship. By way of example, for a radiation crosslinked, $2 \mu \mathrm{m}$ PDMS/PAN membrane the permeance with the base petrol fuel was $0.056 \mathrm{I} \mathrm{m}^{-2} \mathrm{~h}^{-1} \mathrm{kPa}^{-1}$ which is part way between the permeance recorded for pure xylene $\left(0.048 \mathrm{I} \mathrm{m}^{-2} \mathrm{~h}^{-1} \mathrm{kPa}^{-1}\right)$, which is representative of aromatic components, and n-heptane $\left(0.068 \mathrm{I} \mathrm{m}^{-2} \mathrm{~h}^{-1} \mathrm{kPa}^{-1}\right)$, which is representative of paraffin components. The viscosity and estimated solubility parameter of the chosen petrol fuel were respectively 0.52 $\mathrm{mPa} s$ and $17.0 \mathrm{MPa}^{0.5}$, which again fall between corresponding values for $\mathrm{n}$-heptane $(0.40 \mathrm{mPa} \mathrm{s}$ and $\left.15.3 \mathrm{MPa}^{0.5}\right)$ and xylene $\left(0.65 \mathrm{mPa}\right.$ and $\left.18.2 \mathrm{MPa}^{0.5}\right)$. The flux-pressure data for the petrol fuel is wholly consistent with the flux data obtained for the fuel simulants. The inference is that membrane swelling, as dictated by the solubility parameter, and solvent viscosity are the predominant factors governing solvent flux and that the base petrol fuel is predominantly a mixture of low polarity solvents.

\section{Effects of Fuel Composition}

A significant finding of the fuel simulant work was that the level of separation of a particular solvent/solute mixture was due to the membrane swelling induced by the (low polarity) solvent in which the solute was dissolved. The base petrol fuel was evaluated for similar effects by dilution with a particular solvent so as to alter the degree of membrane swelling. The fuel was diluted with either xylene to give a $50 / 50$ by volume solution with an estimated $\delta=17.6 \mathrm{MPa}^{0.5}$, or with heptane to give $\delta=16.4 \mathrm{MPa}^{0.5}$. Noting that solute rejection was independent of solute concentration for the fuel simulants, and thus it is unlikely that a lower concentration of impurities will affect measured fuel clean-up, Figure 7 shows the results obtained from the nanofiltration of these mixtures with a PAN/PDMS membrane.

The effect of fuel composition on clean-up is analogous to the effect of swelling on solute rejection. When the solubility parameter of the fuel is increased by adding xylene to create a mixture more akin to a 'platformate' (i.e. a fuel component rich in aromatic hydrocarbons) the membrane swells less and hence more impurities are removed, albeit at a lower rate as permeate flux is reduced. Similarly, when the solubility parameter becomes closer to that of PDMS by adding n-heptane to create an 'alkylate' (i.e. a fuel component rich in n-alkanes) the membrane swells more and less impurities are removed but at a higher flux. Although reliable swelling measurements with the base fuel proved too problematical, it was possible to measure data for a typical alkylate, a platformate and a radiation crosslinked PDMS/PAN membrane with a $10 \mu \mathrm{m}$ PDMS layer. With the alkylate an average swelling of $16.1 \mu \mathrm{m}$ was recorded whilst the platformate produced a swelling of $11.8 \mu \mathrm{m}$; these correspond to membrane swellings of $16.9 \mu \mathrm{m}$ and $11.9 \mu \mathrm{m}$ for pure $\mathrm{n}$ heptane and pure xylene respectively. The results indicate that fuels with a high aromatic composition are likely to yield good clean-up when treated by PDMS membranes, whereas fuels which are rich in alkane components are more likely to exhibit a lower clean-up albeit at a higher flux.

\section{Effects of Crosslinking and Membrane Type}

The effects of swelling (crosslinking) and membrane type on fuel clean-up and permeance are illustrated in Figures 8 and 9. Figure 8 shows the fuel clean-up obtained as a function of pressure for the base petrol fuel and two PDMS/PAN membranes; Figure 4 shows that the membrane designated 'thermal, $1.5 \mu \mathrm{m}$ ' is the more crosslinked, less swelling, sample. At $500 \mathrm{kPa}$ and 
above, the fuel clean-up obtained with the 'thermal, $1.5 \mu \mathrm{m}$ ' membrane is $25 \%$ higher than that obtained with the membrane designated 'radiation, $2 \mu \mathrm{m}$ ' which is consistent with rejection/degree of swelling concept described earlier. There appears to be a degree of overlap in the data on Figure 8 at lower pressures where the relatively low permeate fluxes obtained with the 'thermal, 1.5 $\mu \mathrm{m}$ ' membrane made measurements more difficult. Whilst precautions were taken, the potential degree of error due to the rate of evaporation relative to the rate of permeate production means that the data obtained at $300 \mathrm{kPa}$ should be viewed with some caution.

Figure 9 shows that the base fuel permeance of the 'thermal, $1.5 \mu \mathrm{m}$ ' membrane $\left(0.018 \mathrm{I} \mathrm{m}^{-2} \mathrm{~h}^{-1}\right.$ $\mathrm{kPa}^{-1}$ ) was approximately one-third of that obtained with the greater swelling 'radiation, $2 \mu \mathrm{m}$ ' membrane $\left(0.054 \mathrm{I} \mathrm{m}^{-2} \mathrm{~h}^{-1} \mathrm{kPa}^{-1}\right)$. A membrane with a PDMS layer thickness of $1 \mu \mathrm{m}$ yielded yet higher flux. It is interesting to note that the polyimide (Starmem 122) membrane exhibited a very low permeance to the base petrol fuel. Figure 4 shows that at $\delta=17.0 \mathrm{MPa}^{0.5}$, i.e. the estimated solubility parameter of the fuel, a swelling of circa $1 \mu \mathrm{m}$ occurs which is only a small fraction of the estimated $75 \mu \mathrm{m}$ selective layer thickness of the membrane. In comparison the PDMS/PAN membranes showed more appreciable swelling (circa 0.75-4 $\mu \mathrm{m}$ ) relative to their starting PDMS thickness $(1-2 \mu \mathrm{m})$. Whilst such results may be coincidental, and fuller interpretations are difficult due to the commercially sensitive nature of membrane manufacture, the evidence suggests that swelling is a critical parameter in determining permeate flux/solute rejection in SRNF.

\section{Effects of Oxygenate Addition}

In many countries oxygenates are used as components in fuel blends to improve the octane rating and/or to produce a more environmentally friendly biofuel. The most common oxygenates are alcohols and ethers. Typical alcohols are methanol and ethanol at concentrations of $20-25 \%$ by volume, with the latter being the most common as it can be produced cheaply via the fermentation of organic materials. Ethers are used at lower concentrations, typically $10-15 \%$, with the most common being methyl-tertiary butyl ether (MTBE) and ethyl-tertiary butyl ether (ETBE). To determine the effects on separation performance, samples of the base petrol fuel were dosed with an oxygenate at a concentration of $20 \%$ by volume.

Typical results of nanofiltration with a PDMS/PAN membrane are shown in Figure 10 where it is evident that alcohol oxygenates are partially rejected to an extent dependent upon the filtration pressure, probably upon sorption into the PDMS layer. The rejection is greatest with methanol $(\delta=$ $\left.29.2 \mathrm{MPa}^{0.5}\right)$ and still significant with ethanol $\left(\delta=26.5 \mathrm{MPa}^{0.5}\right)$. By contrast, the rejection of MTBE $\left(\delta=18.2 \mathrm{MPa}^{0.5}\right)$ was negligible which is to be expected given its molecular dimension and the identical solubility parameter to xylene. Although fuel clean-up increased in all cases with pressure, the addition of an alcohol had a significant effect on the observed clean-up with methanol showing a decrease of $32-45 \%$ and ethanol a decrease of $27-38 \%$. MTBE appeared to have little effect on fuel clean-up. It is interesting to note that pure methanol or ethanol would barely permeate the radiation crosslinked $2 \mu \mathrm{m}$ PDMS/PAN membrane at pressures up to $800 \mathrm{kPa}$ and, although swelling does not dictate the rate a which alcohol can permeate a membrane due to its small molecular dimensions, it seems that some swelling needs to be induced by another, better swelling, solvent for appreciable permeation of both solvents to occur [see also Tarleton et al., 2006b].

Whilst fuels containing MTBE could potentially be treated by nanofiltration without separation of the oxygenate or a reduction in the fuel clean-up, it is clear that difficulties are likely to be encountered when treating alcohol-containing fuels using PDMS membranes (and a 10\% stage-cut). However, there are possible methods for treating such fuels to remove solutes and these include (i) blend in the alcohol after the membrane treatment process and (ii) take the retentate stream as the product. The second scenario also offers the potential to change the octane-rating of a fuel as the retentate will be richer in alcohol than the feed. The reduced clean-up may also be exploited as this will also tend to improve retentate quality. 


\section{Petrol Fuel - Engine Tests}

A sufficient quantity of the base petrol fuel was filtered using a radiation crosslinked PDMS/PAN membrane to allow engine tests to be performed. Whilst full details of the tests cannot be revealed, a petrol engine from a road car was run on the designated fuel (base, permeate, retentate or additivated fuel) for a fixed period with the exhaust gas composition monitored. Following a test, the engine was dismantled to determine the quantities of internal combustion deposits and tests were repeated at least once to confirm the results shown.

Figure 11 shows example photographs of inlet valves after two otherwise identical tests with the base petrol fuel and the permeate obtained from nanofiltration of this fuel. It is clear that the valve exposed to combustion of the permeate fuel is visually cleaner than the valve used with the untreated fuel. The inlet valve deposit (IVD) and combustion chamber deposit (CCD) weights (Figure 12) and carbon monoxide (CO) / nitrous-oxide $\left(\mathrm{NO}_{\mathrm{x}}\right)$ emissions (Figure 13) were also determined. Figure 12 shows that the average IVD weight with the permeate fuel was reduced by $64 \%$ compared to the base fuel, and significantly lower than the IVD weight obtained using the additivated fuel. Interestingly, the retentate also gives lower IVDs than the base fuel. One possible explanation is that IVDs are caused by combinations of a number of impurities when they combust, and that splitting the base fuel into two streams separates these combinations. This hypothesis is supported by the fact that recombining the permeate and retentate streams and performing a subsequent engine test gave an IVD weight the same as that produced with the base fuel. The CCD weights show essentially no difference between the base, permeate and retentate fuels. In general, additivated fuels are expected to exhibit higher CCDs than non-additivated fuels, which is shown to be the case in Figure 12.

The results in Figure 12 indicate that membrane-treated fuel can achieve a significant reduction in IVDs without compromising CCDs as an additivated fuel would do. However, internal engine deposits are not the only factor which relate to overall fuel cleanliness; the quality of the exhaust emissions is also important. The two common exhaust gas characteristics, CO levels and the concentration of $\mathrm{NO}_{x}$, are shown in Figure 13. The $\mathrm{CO}$ levels obtained with the permeate fuel are lower than both the base fuel and the additivated fuel. The $\mathrm{NO}_{\mathrm{x}}$ levels produced by the permeate fuel are $17 \%$ lower than the feed, however, unlike the engine deposits the exhaust-contaminant levels of the retentate fuel are marginally higher than that of the feed. Although the difference in the exhaust compositions for the four fuels is relatively small, the lower $\mathrm{NO}_{\mathrm{x}}$ and $\mathrm{CO}$ levels achieved with the membrane-permeated fuel support (at least) further investigation of nanofiltration as a method of improving fuel quality and could bring about a $10-15 \%$ reduction in overall $\mathrm{NO}_{x} / \mathrm{CO}$ engine emissions.

\section{CONCLUSIONS}

The work presented in this paper has highlighted the key features of SRNF and, by way of example, how the technology could potentially be used to upgrade fuel quality. The principal factors influencing a separation are membrane swelling, as dictated by the difference in solubility parameter between the solvent(s) and the selective membrane material and the extent of membrane crosslinking, solvent properties such as viscosity, the maximum dimensions of the solute(s) present and solvent polarity which can strongly influence individual flux levels.

Separation performance in SRNF is a trade-off between product flux and product quality and a correlation appears to exist between the two for different membranes made from the same material. High solvent fluxes are favoured by greater membrane swelling, higher filtration pressure, thinner selective layers in membranes etc. Greater swelling, however, allows more solutes to pass into the permeate and thus greater membrane crosslinking tends to favour better product (permeate) quality, albeit with the need to provide a greater required membrane area to achieve a given throughput. When polar solvents are present in the feed then separation performance is often compromised, and certainly more complex to interpret. 
Whilst the good correlation between work with fuel simulants and corresponding experiments with 'real' fuel facilitates better understanding, just a potential has been demonstrated to date. It is only recently that polymeric membranes that are capable of maintaining their integrity in non-aqueous environments have become more widely available. With the technology still in its infancy there is much scope for membrane development in terms of, for instance, different materials (e.g. polyvinylidene difluoride (PVDF), poly(1-trimethysilyl-1-propyne) (PTMSP)) and tailoring of membrane swelling characteristics (e.g. by substitution of surface groups) to promote improved solvent flux/solute rejection. The ability to process streams without the addition of thermal energy is particularly attractive in the current economic climate which means that investigations and applications of SRNF will likely increase in the future.

\section{NOMENCLATURE}

$\begin{array}{ll}A_{f} & \text { absorbance of the feed at a given wavelength (absorbance units) } \\ A_{p} & \text { absorbance of the permeate at a given wavelength (absorbance units) } \\ C_{f} & \text { solute concentration in the feed (ppm) } \\ C_{p} & \text { solute concentration in the permeate }(\mathrm{ppm}) \\ \text { CCD } & \text { combustion chamber deposit } \\ \text { CO } & \text { carbon monoxide } \\ \text { ETBE } & \text { ethyl-tertiary butyl ether } \\ \text { IVD } & \text { inlet valve deposit } \\ \text { MTBE } & \text { methyl-tertiary butyl ether } \\ \text { MW } & \text { molecular weight } \\ \text { MWCO } & \text { molecular weight cut-off, of a membrane }\left(\mathrm{g} \mathrm{mol}^{-1}\right) \\ \text { NO } & \text { nitrous-oxide } \\ \text { OM } & \text { organometallic } \\ \text { PAN } & \text { polyacrylonitrile } \\ \text { PDMS } & \text { polydimethylsiloxane } \\ \text { PI } & \text { polyimide } \\ \text { PNA } & \text { poly-nuclear aromatic } \\ \text { SRNF } & \text { solvent resistant nanofiltration } \\ \text { UV-vis } & \text { UV-vis absorption spectroscopy } \\ \delta & \text { solubility parameter (MPa.5) }\end{array}$

\section{REFERENCES}

Bitter J.G.A., Clark R.H., Den Boestert J.L.W.C. and Jayantilal J.B., 1992, Process for reducing the metal content of a hydrocarbon mixture, United States Patent, 5,133,851.

Buckley-Smith M.K., 2006, The use of solubility parameters to select membrane materials for pervaporation of organic mixtures, PhD Thesis, University of Waikato, New Zealand.

Gould R.M., Kloczewski H.A., Menon K.S., Sulpizio T.E. and White L.S., 1997, Lubricating oil dewaxing with membrane separation, United States Patent, 5,651,877.

Hansen C.M., 2007, Hansen Solubility Parameters: A Users Handbook, CRC Press, Boca Raton. Millington C.R. and Nijmeijer A., 2005, Process for upgrading a liquid hydrocarbon stream, United States Patent Application, 20050119517. 
Perkampus H.H., 1992, UV-vis spectroscopy and its applications, Springer-Verlag, Berlin.

Robinson J.P., 2004, The selective removal of components from gasoline using membrane technology, PhD Thesis, Loughborough University.

Robinson J.P., Tarleton E.S., Millington C.R., Nijmeijer A. and Ebert K., 2005, Influence of crosslinking and process parameters on the separation performance of poly(dimethylsiloxane) nanofiltration membranes, Ind. Eng. Chem. Res., 44, 3238-3248.

Scarpello J.T., Nair D., Freitas dos Santos L.M., White L.S. and Livingston A.G., 2002, The separation of homogeneous organometallic catalysts using solvent resistant nanofiltration, $J$. Membrane Sci., 203, 71-85.

Stafie N., Stamatialis D.F. and Wessling M., 2004, Insight into the transport of hexane-solute systems through tailor-made composite membranes, J. Membrane Sci., 228, 103-116.

Tarleton E.S., Robinson J.P., Millington C.R. and Nijmeijer A., 2005a, Non-aqueous nanofiltration: Solute rejection in low-polarity binary systems, J. Membrane Sci., 252, 123-131.

Tarleton E.S., Robinson J.P., Smith S.J. and Na J.J.W., 2005b, A new experimental method for measuring solvent induced swelling in nanofiltration membranes, J. Membrane Sci., 261, 129-135.

Tarleton E.S., Robinson J.P. and Salman M., 2006a, Solvent-induced swelling of membranes measurements and influence in nanofiltration, J. Membrane Sci., 280, 442-451.

Tarleton E.S., Robinson J.P., Millington C.R., Nijmeijer A. and Taylor M., 2006b, The influence of polarity on flux and rejection behaviour in solvent resistant nanofiltration - experimental observations, J. Membrane Sci., 278, 318-327.

Vandezande P., Gevers L.E.M. and Vankelecom I.F.J., 2008, Solvent resistant nanofiltration: separating on a molecular level, Advance article in Chemical Society Reviews, available on the web $8^{\text {th }}$ October 2007.

White L.S., Wormsbecher R.F. and Lesemann M., 2005, Membrane separation for sulphur reduction, United States Patent, 6,896,796.

\section{ACKNOWLEDGEMENTS}

The authors would like to thank GKSS Forschungszentrum, Membrane Extraction Technology and the University of Twente for kindly providing the membranes used in this study. The supporting experimental work of Stephen Bradshaw and Romain Ouharzoune is gratefully acknowledged. 
FIGURES AND TABLES

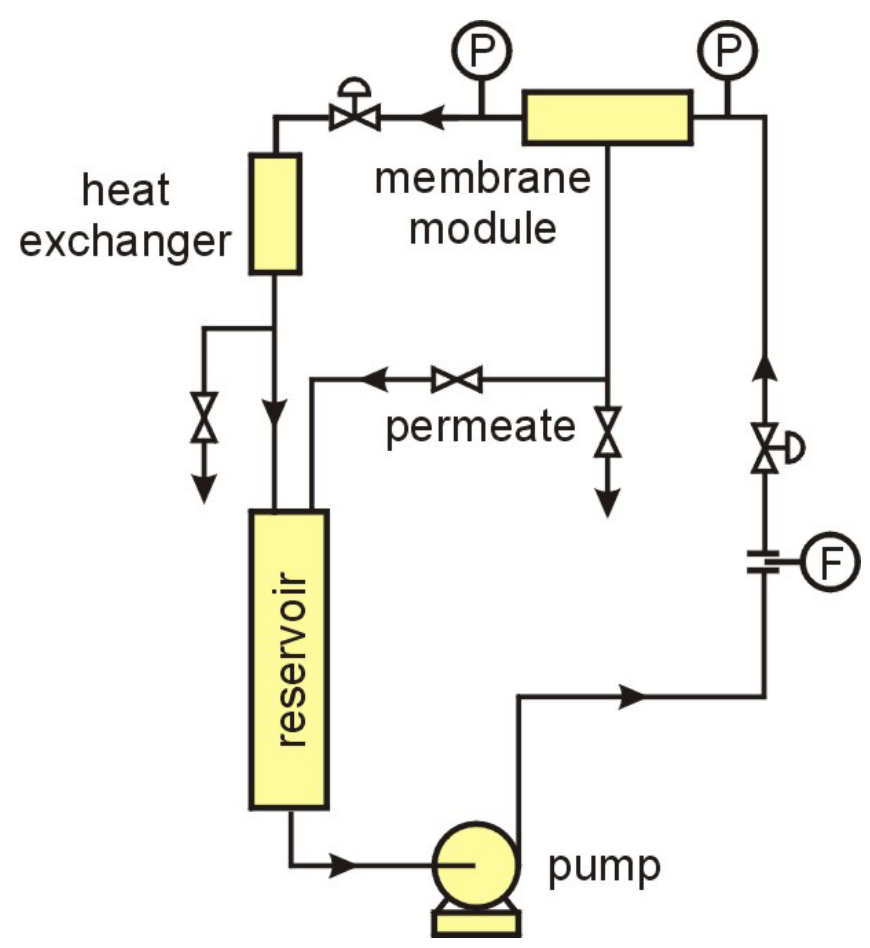

Figure 1: Schematic of the crossflow membrane filtration apparatus.
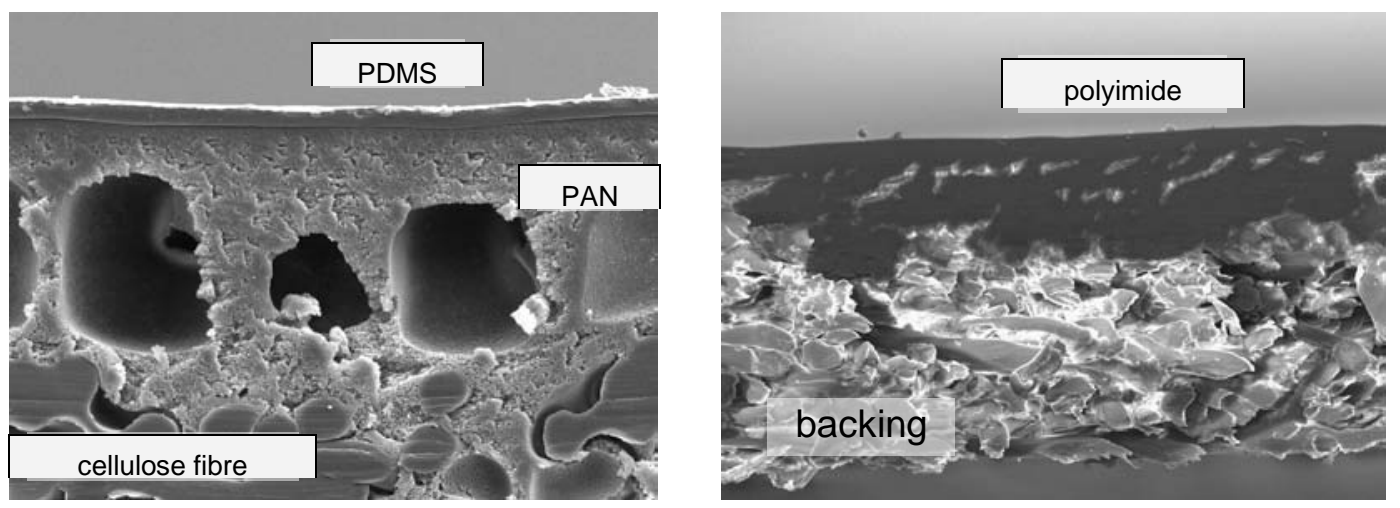

Figure 2: SEM of membrane cross-sections; PDMS/PAN (left) and polyimide (right). 


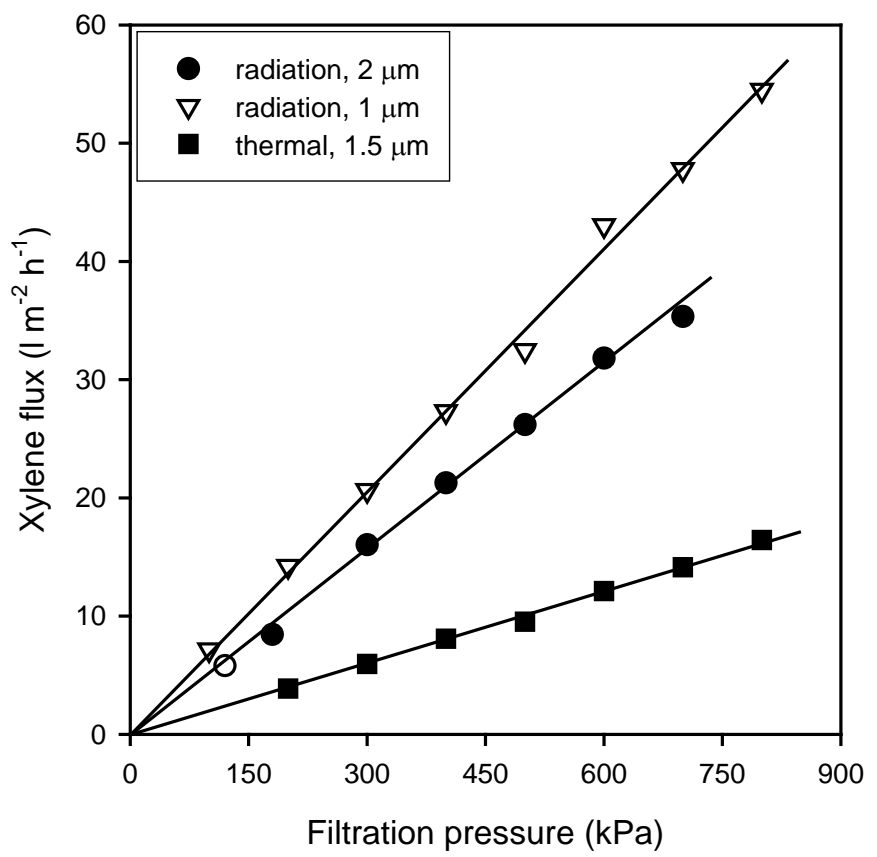

Figure 3: Permeate flux-filtration pressure relationships with xylene solvent for three PDMS/PAN composite membranes; the length dimension on a line legend represents the PDMS thickness before swelling commenced whilst the 'thermal' or 'radiation' designation indicates the primary method by which crosslinking is brought about.

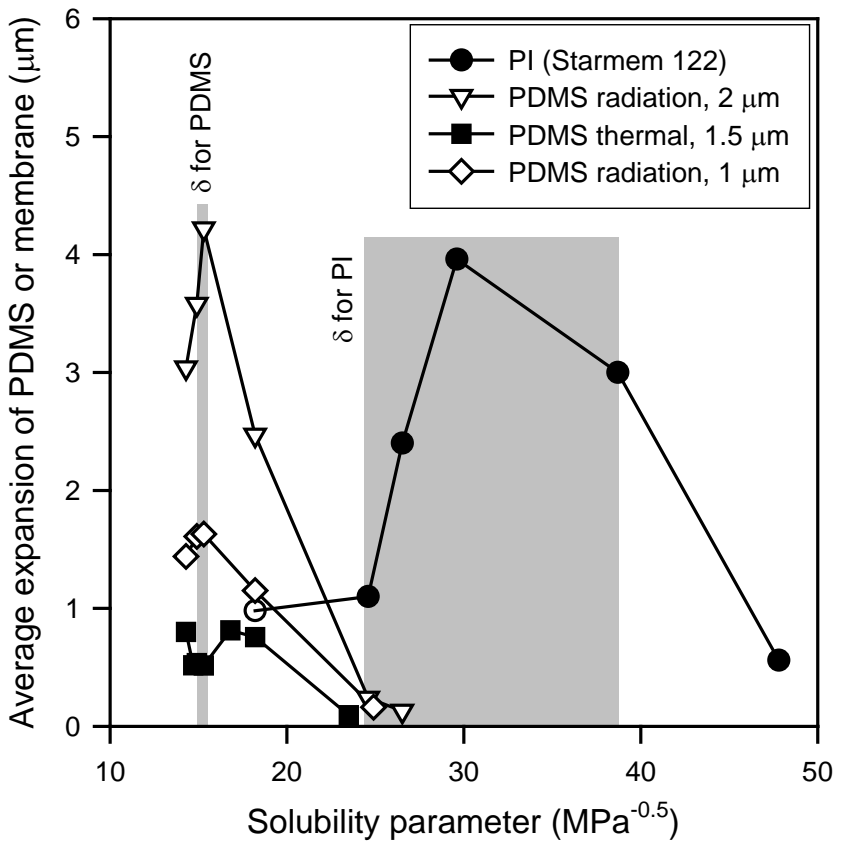

Figure 4: Typical swelling measurements for three PDMS/PAN membranes and a PI membrane; the ranges of solubility parameter $(\delta)$ for PDMS and PI quoted in the literature are highlighted in grey [see Hansen, 2007; Buckley-Smith, 2006]. PAN did not swell to a detectable extent in the solvents tested. 


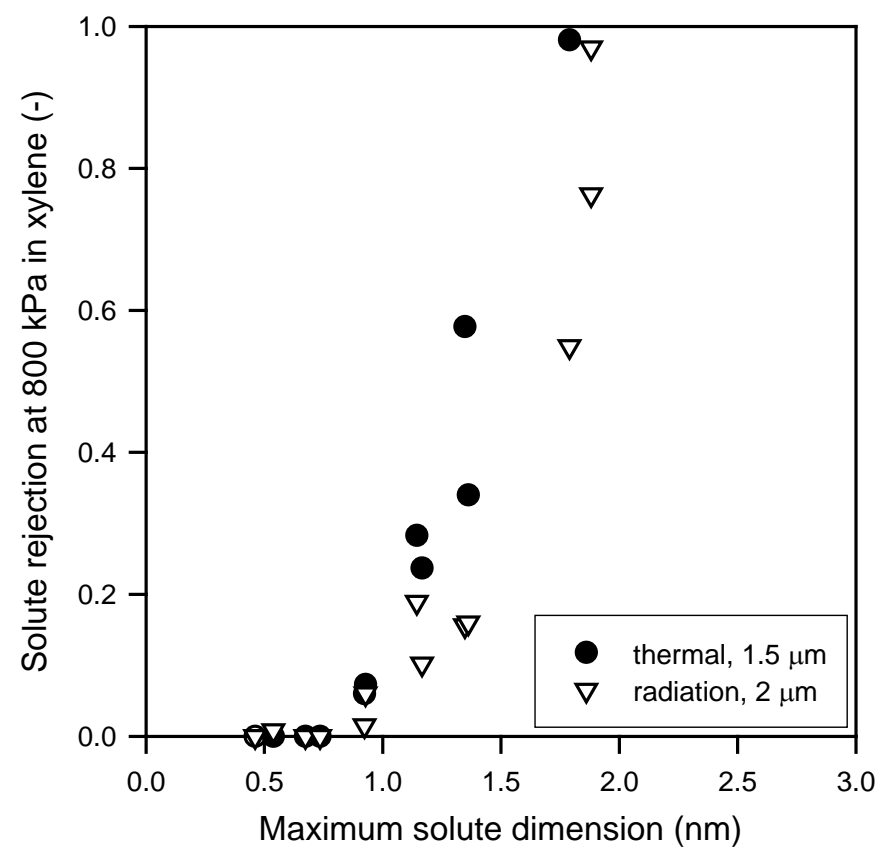

Figure 5: Effect of estimated maximum solute dimension on rejection from a xylene solvent for two PDMS/PAN composite membranes.

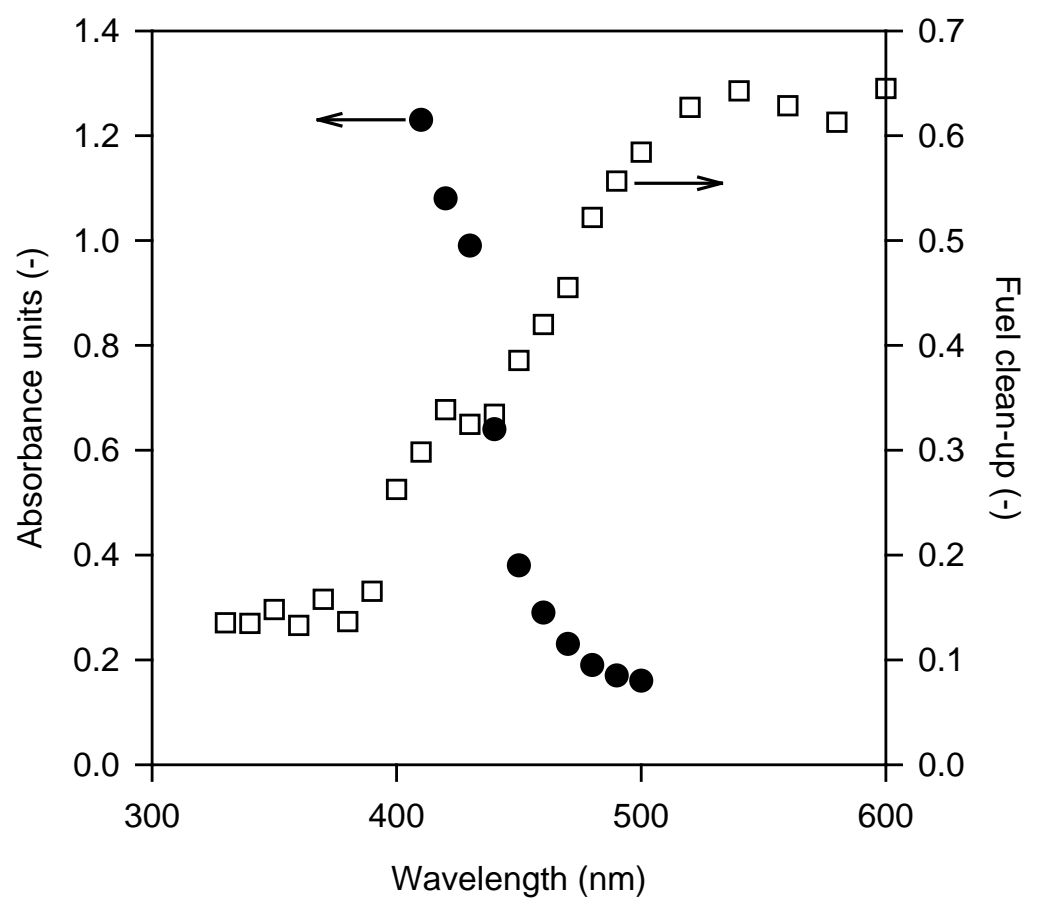

Figure 6: Absorbance and fuel clean-up vs. UV-vis spectroscopy wavelength for the base petrol fuel. 


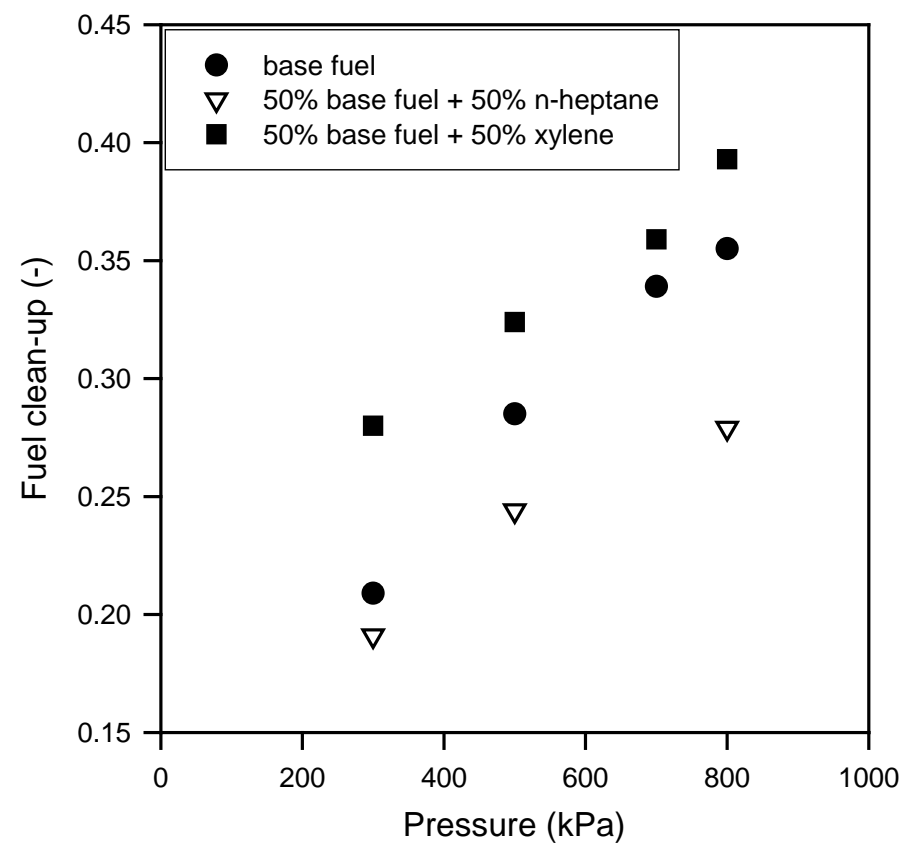

Figure 7: Effect of filtration pressure alkane/aromatic composition on clean-up relative to the base petrol fuel; radiation crosslinked PDMS/PAN composite membrane with a $2 \mu \mathrm{m}$ PDMS selective layer.

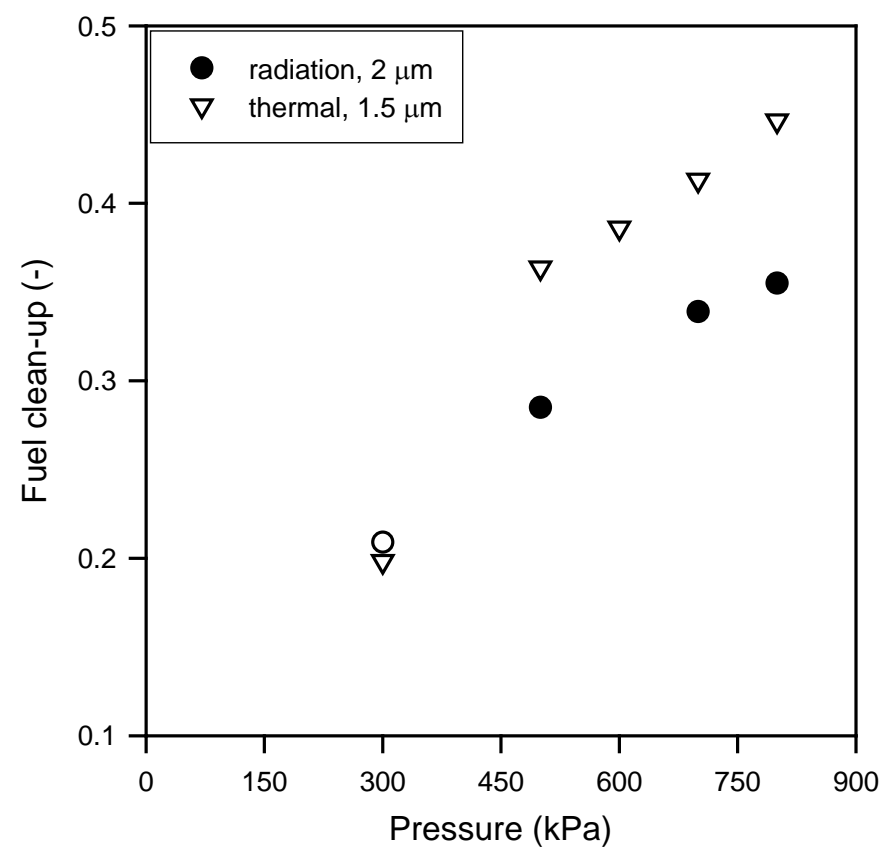

Figure 8: Effect of membrane type on the clean-up for the base petrol fuel for two PDMS/PAN composite membranes. 


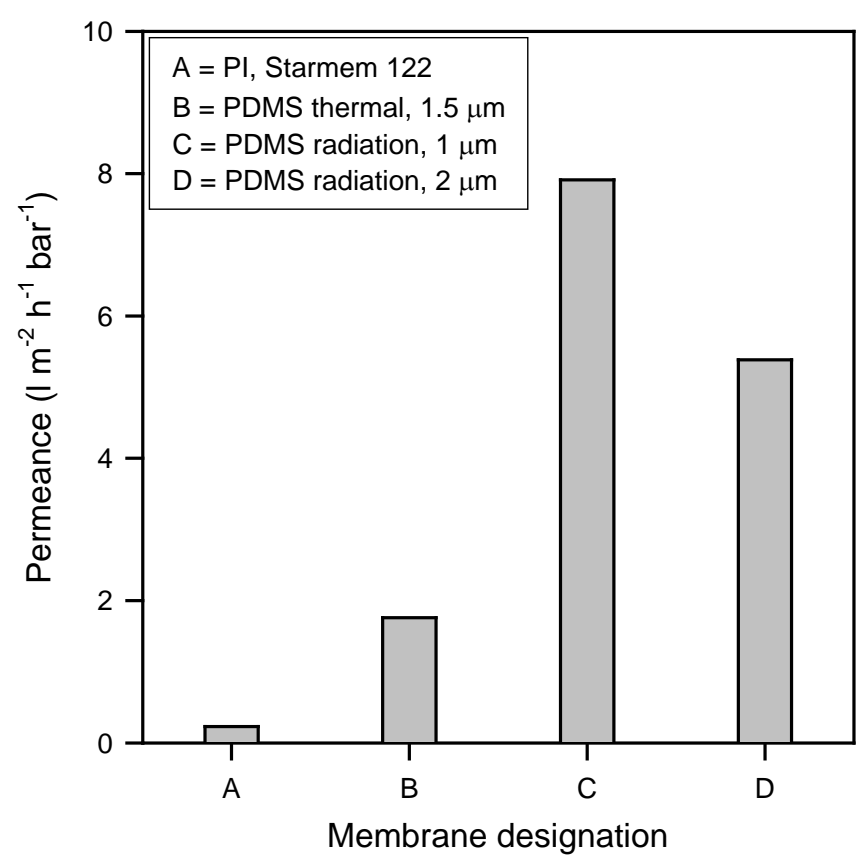

Figure 9: Effect of membrane type on the permeance of the base petrol fuel.

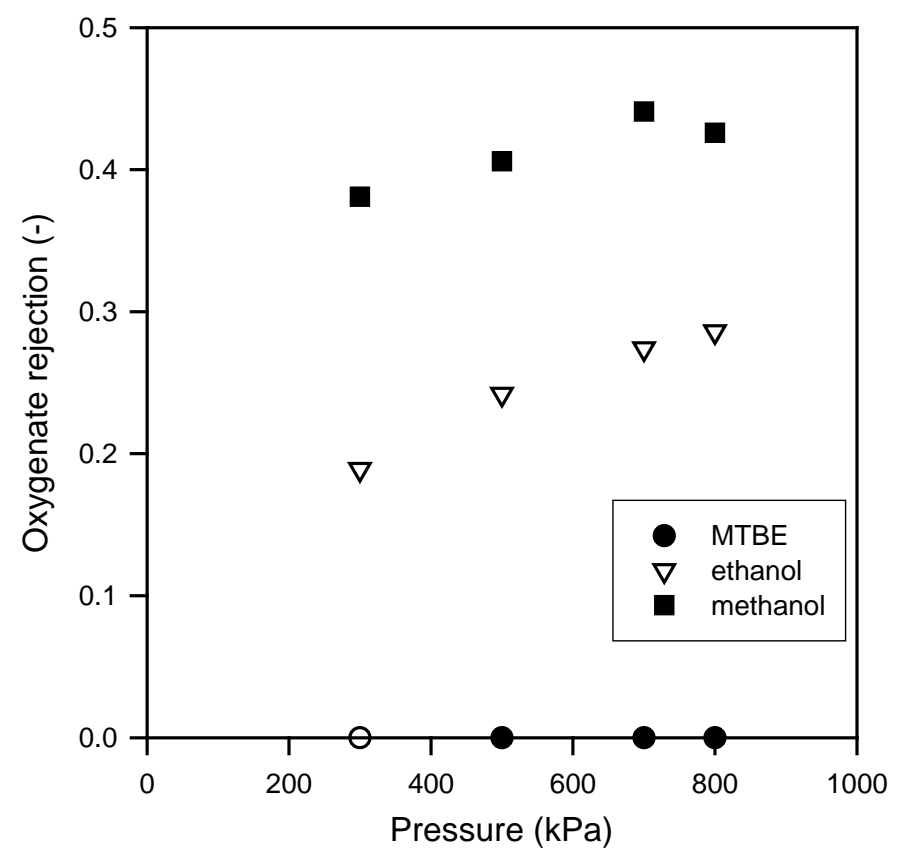

Figure 10: Oxygenate rejection for nanofiltration of the base petrol fuel to which an oxygenate was added to a concentration of $20 \%$ by volume; radiation crosslinked PDMS/PAN composite membrane with a $2 \mu \mathrm{m}$ PDMS selective layer. 


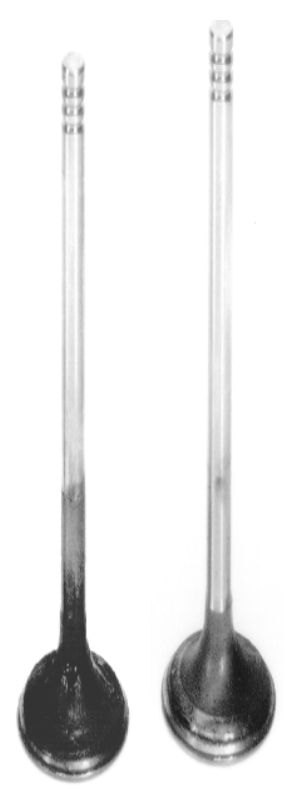

Figure 11: Inlet valves after representative engine tests with the base petrol fuel (left) and membrane treated fuel (i.e. the permeate, right).

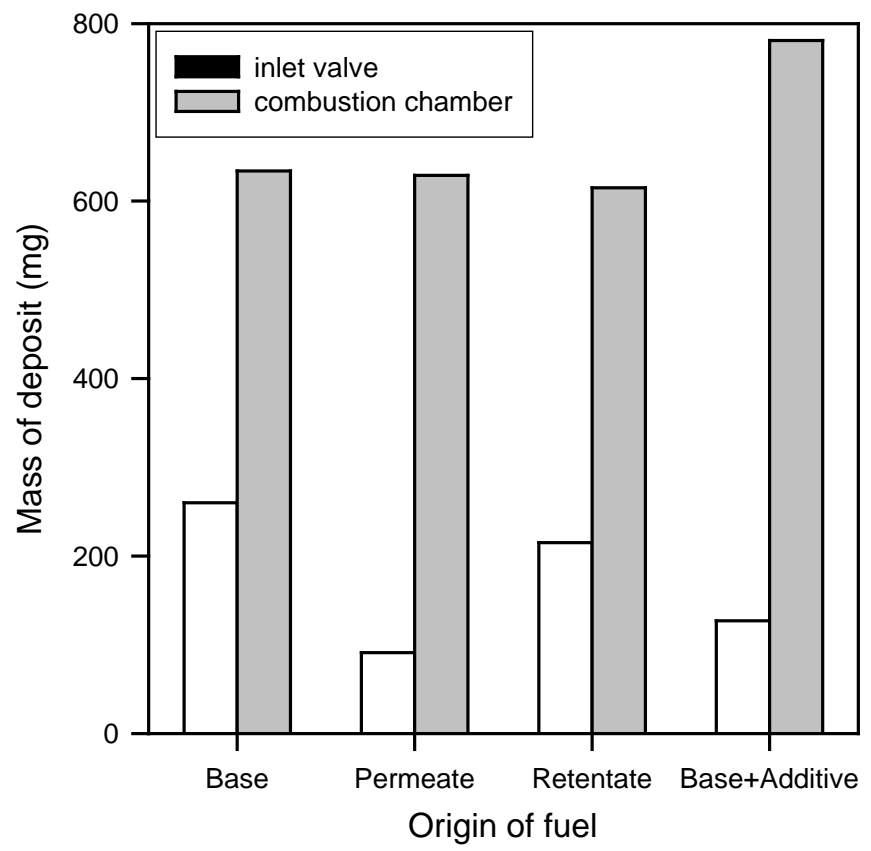

Figure 12: Average amounts of inlet valve and combustion chamber deposits for engine tests with the base petrol fuel, membrane treated fuel and additivated fuel. 


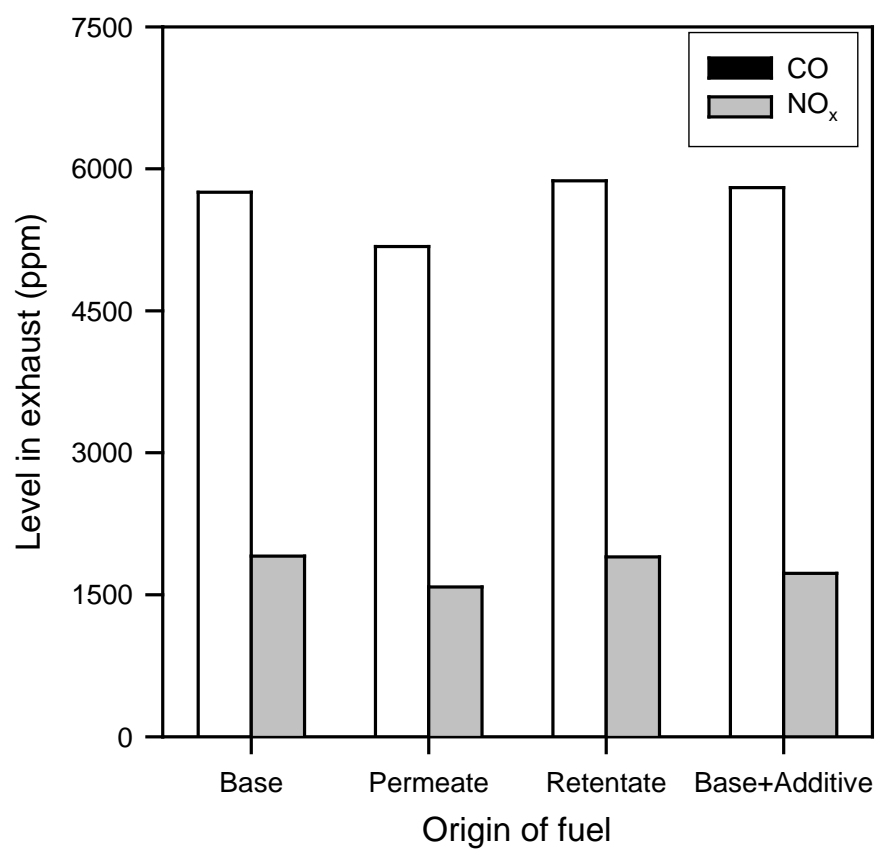

Figure 13: Emission levels for engine tests with four fuel variants. 


\begin{tabular}{|c|c|c|c|c|}
\hline Material & $\begin{array}{l}\text { Molecular } \\
\text { weight } \\
\left(\mathrm{g} \mathrm{mol}^{-1}\right)\end{array}$ & $\begin{array}{c}\text { Viscosity at } \\
20^{\circ} \mathrm{C} \\
(\mathrm{mPa} \mathrm{s})\end{array}$ & $\begin{array}{l}\text { Solubility } \\
\text { parameter } \\
\left(\mathrm{MPa}^{0.5}\right)\end{array}$ & $\begin{array}{c}\text { Max. molecule } \\
\text { dimension } \\
(\mathrm{nm})^{\dagger}\end{array}$ \\
\hline \multicolumn{5}{|l|}{ Membrane } \\
\hline polydimethylsiloxane (PDMS) ${ }^{*}$ & $\mathrm{n} / \mathrm{a}$ & $\mathrm{n} / \mathrm{a}$ & $14.9-15.5$ & $\mathrm{n} / \mathrm{a}$ \\
\hline polyimide $(\mathrm{PI})^{* *}$ & $\mathrm{n} / \mathrm{a}$ & $\mathrm{n} / \mathrm{a}$ & $24.3-38.7$ & $\mathrm{n} / \mathrm{a}$ \\
\hline \multicolumn{5}{|l|}{ Solvent } \\
\hline i-octane & 114 & 0.46 & 14.3 & 0.928 \\
\hline n-hexane & 86 & 0.31 & 14.9 & 0.805 \\
\hline n-heptane & 100 & 0.39 & 15.3 & 0.928 \\
\hline cyclohexane & 84 & 0.95 & 16.8 & 0.497 \\
\hline xylene & 106 & 0.65 & 18.2 & 0.653 \\
\hline methyl-tertiary butyl ether (MTBE) & 88 & 0.27 & 18.2 & 0.430 \\
\hline i-propanol & 60 & 2.40 & 23.6 & 0.374 \\
\hline n-propanol & 60 & 2.30 & 24.9 & 0.540 \\
\hline ethanol & 46 & 1.15 & 26.5 & 0.355 \\
\hline methanol & 32 & 0.55 & 29.2 & 0.244 \\
\hline water & 18 & 1.00 & 47.8 & 0.149 \\
\hline base petrol fuel & unknown & 0.52 & $17.0^{\dagger \dagger}$ & unknown \\
\hline \multicolumn{5}{|l|}{ Solute } \\
\hline thiophene & 84 & $\mathrm{n} / \mathrm{a}$ & $\mathrm{n} / \mathrm{a}$ & 0.461 \\
\hline 1-butanethiol & 90 & $\mathrm{n} / \mathrm{a}$ & $\mathrm{n} / \mathrm{a}$ & 0.735 \\
\hline acenaphthene (PNA) & 154 & $\mathrm{n} / \mathrm{a}$ & $\mathrm{n} / \mathrm{a}$ & 0.674 \\
\hline ferrocene $(\mathrm{OM})$ & 186 & $\mathrm{n} / \mathrm{a}$ & $\mathrm{n} / \mathrm{a}$ & 0.538 \\
\hline pyrene (PNA) & 202 & $\mathrm{n} / \mathrm{a}$ & $\mathrm{n} / \mathrm{a}$ & 0.923 \\
\hline coronene (PNA) & 300 & $\mathrm{n} / \mathrm{a}$ & $\mathrm{n} / \mathrm{a}$ & 0.928 \\
\hline 9,10-diphenylanthracene (PNA) & 330 & $\mathrm{n} / \mathrm{a}$ & $\mathrm{n} / \mathrm{a}$ & 1.362 \\
\hline 1,1,2,2-tetraphenylethylene (PNA) & 332 & $\mathrm{n} / \mathrm{a}$ & $\mathrm{n} / \mathrm{a}$ & 1.166 \\
\hline iron (III) acetylacetonate (OM) & 353 & $\mathrm{n} / \mathrm{a}$ & $\mathrm{n} / \mathrm{a}$ & 1.144 \\
\hline iron (III) naphthenate (OM) & 373 & $\mathrm{n} / \mathrm{a}$ & $\mathrm{n} / \mathrm{a}$ & 1.790 \\
\hline rubrene (PNA) & 532 & $\mathrm{n} / \mathrm{a}$ & $\mathrm{n} / \mathrm{a}$ & 1.348 \\
\hline copper (II) naphthenate (OM) & 612 & $\mathrm{n} / \mathrm{a}$ & $\mathrm{n} / \mathrm{a}$ & 1.881 \\
\hline
\end{tabular}

${ }^{\dagger}$ estimated with ChemDraw ${ }^{\circledR}$ 3D Pro $11.0 ;{ }^{\dagger \dagger}$ estimated by assuming that solubility parameter can be represented as $15.3 \mathrm{MPa}^{0.5}$ for alkanes and $18.2 \mathrm{MPa}^{0.5}$ for aromatics, the contribution due to olefins is ignored; * available on a PAN backing with an as manufactured selective PDMS layer thickness of $1 \mu \mathrm{m}$, $1.5 \mu \mathrm{m}, 2 \mu \mathrm{m}$ or $10 \mu \mathrm{m}$ (1.5 $\mu \mathrm{m}$ membrane thermally crosslinked, others radiation crosslinked); selective PI layer thickness estimated to be $75 \mu \mathrm{m}$ (Starmem 122);

Table 1: Some properties of the test materials. 